\title{
Extraction Methodology and Power Ultrasound Effects on Phenolic Compounds and Antioxidant Activities of Two Tunisian Grape Varieties
}

\author{
Saada Mariem ${ }^{1 *}$, Ben Salem-Berrabah olfa ${ }^{2}$, Wasli Hanen${ }^{1}$, Jlassi Ammal ${ }^{1}$, and Ksouri Riadh ${ }^{1}$ \\ ${ }^{1}$ Laboratoire des Plantes Aromatiques et Médicinales, Centre de Biotechnologie de Borj-Cédria, BP 901,2050 \\ Hammam-lif, Tunisie. \\ ${ }^{2}$ Research Laboratory in Environmental Science and Technology. High Institute of Sciences and Technologies \\ of the Environment. ISSTE University of Cartage, Borj Cedria Tunis. \\ *Corresponding Author: Saada Mariem, Laboratoire des Plantes Aromatiques et Médicinales, Centre \\ de Biotechnologie de Borj-Cédria, BP 901, 2050 Hammam-lif, Tunisie.
}

\begin{abstract}
Two cultivated grape varieties in Tunisia were investigated for their phenolic and antioxidant activities contents in the aim to inspect maceration and ultrasound-assisted system influences as extraction methodologies. The effect of the increasing ultrasonic power on these components were also assessed. In fact, the superiority of the ultrasound-assisted technique to extract phenolic compounds and improve antioxidant activities, was clearly as compared to conventional extraction. Besides, dried plants showed a better phenolic conservation and an important antioxidant power as compared to fresh plants. Regardless of the extraction technique used and the state of the fruit, red grape showed a better phenolic quantities and the utmost antioxidant capacities in comparison to green one. On the other hand, the increasing ultrasound power applied seems to have less influence on antioxidant parameters. The chromatogram analysis reveals the presence of phenolic acids and flavonoids. These findings highlights the superiority of non-conventional extraction system.
\end{abstract}

Keywords: antioxidant activities, grapes, phenolic compounds, RP-HPLC, Ultrasound extraction

\section{INTRODUCTION}

Antioxidant metabolites contribute effectively to autoxidation inhibition in aliments and biological systems [1]. Phenolic compounds like flavonoids and phenolic acids are an essential part of the human nutrition, and are of substantial interest due to their capacity for neutralizing free radicals like hydroxyl radical and superoxide anion radical, which can generate divers diseases, such as arteriosclerosis, autoimmune, cancer and neurodegenerative syndromes [2]. Moreover, natural antioxidants from plants could conserve the quality of food products from lipid rancidity and chemical oxidation as more healthy and secure additives compared with synthetic ones [ $3 ; 4]$. Thus, several process steps must be optimized to obtain natural antioxidants and respond to the industrial purposes. Among those steps, extraction is the first, crucial and important stage for the isolation, identification and valorization of antioxidant compounds [5]. The recuperation of these compounds is usually achieved through the conventional extraction method and the concentration of solvent. Some parameters such as temperature and time are major factors to be optimized for maximum recuperation of the targeted compounds [6]. Solvent extraction is dependent on the solvent nature and the extraction technique due to the differences in polarity of the antioxidants. Several traditional extraction methods have been reported for the extraction of antioxidant molecules from different matrices using solvents with different polarities [7;8].

Recently new extraction techniques (non conventional methods) such as ultrasound, microwave assisted extraction and supercritical fluid extraction were performed [9]. Ultrasound-assisted extraction is one of the most economical and efficient techniques. In fact, it enhances the efficiency of functional compounds' extraction, reduces extraction time, and provides more processing efficiency [10]. Sound waves with the frequency superior to $20 \mathrm{kHz}$ induce mechanical vibrations in liquids, gases and solids [11]. Cavitation phenomenon as an issue of ultrasonication defined as generated growth, and collapse of the gas steam-filled bubbles in a liquid. Cavitation provokes rotational flow and disorder in a liquid that culminates to significant raise in mass transfer [7]. 
Ultrasound also offers a mechanical effect allowing greater penetration of solvent into the sample matrix. By increasing the contact surface area between the solid and liquid phase, the solute quickly diffuses from the solid phase to the solvent [12]. Cho et al (2006) have proved that the utilization of ultrasound-assisted extraction in grape skin can improve the recovery of functional compounds up to $30 \%$ as compared to traditional solvent extraction [13]. In addition, the use of ultrasound-assisted extraction also prevents the possible chemical degradation of targeted compounds [9].

Grape (Vitis vinifera) is one of the most cultivated fruit in the world. The consumption of grapes and grape products is raising because of the associated health benefits [14]. In fact, 75\% of grape polyphenols exist in its peels and seeds testifying of the wealth of grapes in phenolic compounds [15]. The beneficial health effects related to the consumption of grape and grape derivatives are principally due to the biological capacities of the occurring phenolic species [16]. Natural antioxidant could be exploited in diverse therapeutic procedures with the objective of free radical neutralization in natural systems [17] and oxidation of human low-density lipoproteins [18].

In this study, the phenolic contents and the antioxidant activities of two Tunisian grape varieties extract obtained by maceration and ultrasonic-assisted extraction methods using as solvent the ethanol $80 \%$ are studied. The beneficial compounds contents of the extracts are assessed to define the most performing extraction technique. The effects of increasing power ultrasonic (40 to $100 \%$ ) on these parameters are also investigated.

\section{Materials AND Methods}

\subsection{Plant Sampling and Preparation of Extracts}

Grape samples (Red globe et Muscat d'Italie) were collected from the region of Laaroussa (Séliana) in 2015. The fresh fruits were conserved at $-20^{\circ} \mathrm{C}$ before chemical analysis. For the maceration, extracts were obtained by magnetic stirring of $2.5 \mathrm{~g}$ samples in $25 \mathrm{ml} 80 \%$ ethanol for $30 \mathrm{~min}$ [8]. Regarding the ultrasound-assisted extraction, the process was carried out in an ultrasonic bath (Sonorex Digital 10 $\mathrm{P}$, Bandelin) at $100 \%$ power. Samples $(2 \mathrm{~g})$ were placed into Erlenmeyer flasks $(250 \mathrm{~mL})$. Samples were exhaustively extracted with $80 \%$ ethanol for $30 \mathrm{~min}$ at $35^{\circ} \mathrm{C}$ [8]. Moreover, the power of the ultrasonic bath has been varied (40, 60, 80 and $100 \%$ Watt). For both extraction methods, the mixtures were kept for $24 \mathrm{~h}$ at $4^{\circ} \mathrm{C}$ and filtered using a Whatman $\mathrm{N}^{\circ} 4$ filter paper. Extracts were stored at $4^{\circ} \mathrm{C}$ until analysis.

\subsection{Colorimetric Quantification of Antioxidants}

\subsubsection{Total Phenolic Content}

Colorimetric quantification of total polyphenols was determined as described by Dewanto et al. (2002) [19]. An aliquot $(0.125 \mathrm{ml})$ of appropriately diluted sample extract was mixed with $0.5 \mathrm{ml}$ distilled water and $0.125 \mathrm{ml}$ of Folin-Ciocalteu reagent. After $3 \mathrm{~min}, 1.25 \mathrm{ml}$ of $\mathrm{Na}_{2} \mathrm{CO}_{3}$ solution (7\%) were added and the final volume was adjusted to $3 \mathrm{ml}$ with distilled water. The absorbance of the resulting solution was measured at $760 \mathrm{~nm}$, after incubation for $90 \mathrm{~min}$. The phenols contents were expressed in terms of milligrams gallic acid equivalent per gram of dry weight or fresh weight (mg GAE/g DW or mg $\mathrm{GAE} / \mathrm{g}$ FW). Triplicate measurements were taken for all samples.

\subsubsection{Total Flavonoid Content}

Total flavonoids were measured by a colorimetric assay according to Dewanto et al. (2002) [19]. An aliquot of suitable diluted samples was added to $0.075 \mathrm{ml}$ of $\mathrm{NaNO}_{2}$ solution (5\%), mixed and left for $6 \mathrm{~min}$, before adding $0.15 \mathrm{ml}$ of a freshly prepared $\mathrm{AlCl}_{3}$ solution (10\%). After $5 \mathrm{~min}, 0.5 \mathrm{ml}$ of $\mathrm{NaOH}$ (1 M) solution was added. The final volume was adjusted to $2.5 \mathrm{ml}$ with distilled water and thoroughly mixed. Absorbance of the mixture was immediately determined at $510 \mathrm{~nm}$. Total flavonoids content were expressed as $\mathrm{mg}$ catechin per gram of dry weight or fresh weight (mg CE/g DW or mg CE/g FW). All samples were analyzed in triplicate

\subsubsection{Total Condensed Tannins Assay}

The analysis of condensed tannins (Proanthocyanidins) was carried out according to the method of Sun et al. (1998) [20]. Three milliliters of $4 \%$ methanol vanillin solution and $1.5 \mathrm{ml}$ of concentrated $\mathrm{HCl}$ were added to $0.05 \mathrm{ml}$ of suitably diluted sample. The mixture was allowed to stand for $15 \mathrm{~min}$, and the 
absorbance was measured at $500 \mathrm{~nm}$ against blank. Total condensed tannins were expressed was expressed as mg catechin per gram of dry weight or fresh weight (mg CE/g DW or mg CE/g FW). All samples were analyzed in triplicate.

\subsection{Assessment of Antioxidant Activities}

\subsubsection{Evaluation of Total Antioxidant Capacity}

The assay is based on the reduction of $\mathrm{Mo}(\mathrm{VI})$ to $\mathrm{Mo}(\mathrm{V})$ by the extract and subsequent formation of a green phosphate/Mo $(\mathrm{V})$ complex at acid $\mathrm{pH}$ [21]. An aliquot $(0.1 \mathrm{ml})$ of extracts was combined to 1 $\mathrm{ml}$ of reagent solution $(0.6 \mathrm{M}$ sulfuric acid, $28 \mathrm{mM}$ sodium phosphate and $4 \mathrm{mM}$ ammonium molybdate). The tubes were incubated at $95^{\circ} \mathrm{C}$ for $90 \mathrm{~min}$. After that, the mixture was cooled to room temperature and the absorbance of each solution was measured at $695 \mathrm{~nm}$ against a blank. The antioxidant capacity was expressed as mg gallic acid equivalent per gram of dry weight or fresh weight (mg GAE/g DW or mg GAE/g FW). All samples were analyzed in triplicate.

\subsubsection{DPPH Quenching Ability}

The radical scavenging activity of the extracts was measured using the DPPH (1.1-diphenyl-2picrylhydrazyl) method according to Hanato et al. (1988) [22]. For this, $1 \mathrm{ml}$ of the extracts at various concentrations was mixed with $0.25 \mathrm{ml}$ of a DPPH-methanolic solution $(0.2 \mathrm{mM})$ and allowed to react in the dark for $30 \mathrm{~min}$, then the absorbance of the resulting solution was read at $517 \mathrm{~nm}$. The antiradical activity was determined using the formula (1):

DPPH scavenging activity $(\%)=\left[\left(\mathrm{A}_{0}-\mathrm{A}_{1}\right) / \mathrm{A}_{0}\right] * 100$

Where $A_{0}$ is the absorbance of the control at $30 \mathrm{~min}$, and $A_{1}$ is the absorbance of the sample at $30 \mathrm{~min}$. The antiradical activity was expressed as $\mathrm{IC}_{50}(\mu \mathrm{g} / \mathrm{ml})$. All samples were analyzed in triplicates.

\subsubsection{Reducing Power}

The ability of the extracts to reduce $\mathrm{Fe}^{3+}$ was assayed by the method of Oyaizu (1986) [23]. Briefly, 1 $\mathrm{ml}$ of extracts was mixed with $2.5 \mathrm{ml}$ of phosphate buffer $\left(0.2 \mathrm{M}\right.$, pH 6.6) and $2.5 \mathrm{ml}$ of $\mathrm{K}_{3} \mathrm{Fe}(\mathrm{CN})_{6}$ $(1 \%)$. After incubation at $50^{\circ} \mathrm{C}$ for $20 \mathrm{~min}, 2.5 \mathrm{ml}$ of trichloroacetic acid $(10 \%)$ was added and the mixture was centrifuged at $650 \mathrm{x}$ g for $10 \mathrm{~min}$. Finally, $2.5 \mathrm{ml}$ of the upper layer was mixed with 2.5 $\mathrm{ml}$ of distilled water and $0.5 \mathrm{ml}$ of aqueous $\mathrm{FeCl}_{3}(0.1 \%)$, then absorbance was measured at $700 \mathrm{~nm}$. A

higher absorbance indicates a higher reducing power. Results are expressed as $\mathrm{EC}_{50}$ value $(\mu \mathrm{g} / \mathrm{ml})$ which is the effective concentration giving an absorbance of 0.5 and was obtained from linear regression analysis. All samples were analyzed in triplicate.

\subsection{4. $\beta$-Carotene Bleaching Test (BCBT)}

A modification of the method described by Koleva et al. (2002) was employed [24]. $\beta$-Carotene (2 $\mathrm{mg}$ ) was dissolved in $20 \mathrm{ml}$ chloroform and to $4 \mathrm{ml}$ of this solution, linoleic acid $(40 \mathrm{mg}$ ) and Tween $40(400 \mathrm{mg})$ were added. Chloroform was evaporated under vacuum at $40^{\circ} \mathrm{C}$ and $100 \mathrm{ml}$ of oxygenated ultra-pure water was added, then the emulsion was vigorously shaken. An aliquot (150 $\mu \mathrm{l})$ of the $\beta-$ carotene/linoleic acid emulsion was distributed in each of the wells of 96-well plate and solutions of the test samples $(10 \mu \mathrm{l})$ were added. Three replicates were prepared for each sample. The plates were incubated at $50{ }^{\circ} \mathrm{C}$ for $120 \mathrm{~min}$. Absorbance was measured immediately $(\mathrm{t}=0 \mathrm{~min})$ and after incubation $(\mathrm{t}=120 \mathrm{~min}$ ) using a model EAR 400 plate reader (Labsystems Multiskan MS) at $470 \mathrm{~nm}$. The $\beta$ carotene bleaching ability of the extracts was determined using the formula (2):

Inhibition $(\%)=\left[\left(\mathrm{A}_{\mathrm{s}(120)}-\mathrm{A}_{\mathrm{c}(120))}\right) /\left(\mathrm{A}_{\mathrm{c}(0)}-\mathrm{A}_{\mathrm{c}(120))}\right)\right]^{*} 100$

where $\mathrm{A}_{\mathrm{c}(0)}$ and $\mathrm{A}_{\mathrm{c}(120)}$ are the absorbance values of the control at 0 and $120 \mathrm{~min}$, respectively, and $\mathrm{A}_{\mathrm{s}(120)}$ is the sample absorbance at $120 \mathrm{~min}$. The results were expressed as $\mathrm{IC}_{50}$ values $(\mu \mathrm{g} / \mathrm{ml})$.

\subsection{Phenolic Identification by RP-HPLC}

The extract related to the most interesting growth stage was injected to RP-HPLC. The separation of phenolics was performed with an Agilent 1100 series HPLC system equipped with on-line degasser (G 1322A), quaternary pump (G 1311A), a thermostatic autosampler (G 1313A), column heater (G 1316A) and diode array detector (G 1315A). Instrument control and data analysis were carried out using Agilent HPLC Chemstation 10.1 editon through Windows 2000. The separation was carried out on a reverse 
phase ODS C18 (4 mm, $250 \times 4.6 \mathrm{~mm}$, Hypersil) column used as stationary phase at ambient temperature. The mobile phase consisted of acetonitrile (solvent A) and sulphuric acid $(0.2 \mathrm{ml} / 100 \mathrm{ml}$ water) (solvent $\mathrm{B}$ ). The flow rate was kept at $0.5 \mathrm{ml} / \mathrm{min}$. The gradient program was as follows: $15 \%$ A/85\% B 0-12 min, 40\% A/60\% B 12-14 min, 60\% A/ 40\% B 14-18 min, 80\% A/20\% B 18-20 min, $90 \%$ A/10\% B 20-24 min, 100\% A 24-28 min. The injection volume was $20 \mu 1$ and peaks were monitored at $280 \mathrm{~nm}$. Peak identification was obtained by comparing the retention time and the UV spectra of the interesting fraction phenolics chromatogram with those of pure standards which were purchased from Sigma (St. Louis, MO, USA) [25].

\subsection{Statistical Analysis}

For all plant parameters, three replicates were used. To determine the relative importance of development stage on phenolic content and antiradical activities, a two-way analysis of variance (ANOVA) was achieved for whole data, using the SAS system (1990) software, Version 6 (SAS Institute Inc., Cory, NJ). Means were compared using the Duncan's multiple range test at the $\mathrm{P}<0.05$ level, when significant differences were found.

\section{RESULTS AND DISCUSSION}

\subsection{Conventional Extraction Method Versus Ultrasound Assisted Extraction (UAE) Effect on Phenolic Contents and Antioxidant Capacities of Two Verities Fresh Grapes}

\subsubsection{Total Phenolic, Flavonoid and Tannins Contents}

In the first step of this study, two methods (conventional and ultrasound-assisted extraction) were used to extract polyphenols from two fresh grapes (Red Globe and Muscat d'Italie). In case of ultrasonic extraction, the extraction was carried out at constant power (100\%). Total polyphenol, flavonoid and tannin contents of Red and Green grape obtained by conventional method and ultrasound assisted extraction are shown in Table 1. Red grapes are rich in polyphenols, flavonoids and condensed tannins in comparison to green grapes (1.94 mg EAG/g FW, 0.64 and $2.42 \mathrm{mg}$ EC/g FW than $1.45 \mathrm{mg}$ EAG, 0.356 and $1,48 \mathrm{mg} \mathrm{EC} / \mathrm{g} \mathrm{FW}$ respectively). Compared to the classical method, ultrasound assisted extraction recoveries obtained were significantly higher for the amount of total polyphenols, flavonoids and condensed tannins regardless grape variety. The mechanism for ultrasonic enhancement can be attributed to an intensification of mass transfer due to the collapse of cavitation bubbles near cell walls. In fact, ultrasound can break down the cell walls and improved the contact between solvent and plant material. In addition, when cavitation bubbles collapse an ultrasonic jet is created and will act like a solvent micropump that can force a solvent into the cell to dissolve the components [26;27].

Phenolic content in plant depends on a number of intrinsic (genotype, ontology), extrinsic (agronomic, environmental, postharvest handling and storage) factors and mostly on technological factors such as the extraction method applied [28]. Many studies showed that ultrasound can improve the extraction of phenolic compounds from plant material. Kan et al. (2010) showed that total phenolic content from orange peel obtained by UAE during 15 min was significantly higher than by Soxhlet extraction during 60 min [29]. Herrera and Luque De Castro (2004) extracted from strawberries, using 0.8 s duty cycle for $30 \mathrm{~s}$, phenolic compounds such as rutin, naringin, naringenin, quercetin, ellagic acid and kaempferol by developing semiautomatic method based on ultrasounds [30]. Li et al. (2005) found that the recovery of chlorogenic acid from fresh leaves, fresh bark and dried bark of Eucommia ulmodies Oliv. was improved using UAE at optimized condition (70\% methanol, 20:1 solvent, sample ratio and 30 min time) than conventional extraction techniques [31]. Yang and Zhang (2008) extracted bioactive compounds like rutin and quercetin from Euonymus alatus (Thund.) Sieb using optimized sonication condition and showed that ultrasonic method had better extraction efficiency than conventional methods [32].

Table1. Antioxidant activity of Red and Green grapes obtained by maceration and ultrasound assisted extraction. TPC: Total polyphenol content, TFC: total flavonoid content, CTC: Condensed tannins content and TAA: Total antioxidant activity. Means of three replicates followed by at least one same letter are not significantly different at $P<0.05$

\begin{tabular}{|l|l|l|l|l|}
\hline Sample & \multicolumn{2}{|l|}{ Maceration } & \multicolumn{2}{l|}{$\begin{array}{l}\text { Ultrasound-assisted } \\
\text { extraction }\end{array}$} \\
\hline & Red grape & Green grape & Red grape & Green grape \\
\hline TPC $($ mgEAG/gDW) & $1.935^{\mathrm{b}}$ & $1.446^{\mathrm{d}}$ & $3.052^{\mathrm{a}}$ & $1.762^{\mathrm{c}}$ \\
\hline TFC $(\mathbf{m g E C} /$ gDW $)$ & $0.635^{\mathrm{b}}$ & $0.356^{\mathrm{c}}$ & $0.967^{\mathrm{a}}$ & $0.612^{\mathrm{b}}$ \\
\hline
\end{tabular}


Extraction Methodology and Power Ultrasound Effects on Phenolic Compounds and Antioxidant Activities of Two Tunisian Grape Varieties

\begin{tabular}{|l|l|l|l|l|}
\hline CTC $(\mathbf{m g E C} / \mathbf{g D W})$ & $2.418^{\mathrm{b}}$ & $1.477^{\mathrm{d}}$ & $3.410^{\mathrm{a}}$ & $1.985^{\mathrm{c}}$ \\
\hline TAA $(\mathbf{m g E A G / g F W )}$ & $4.683^{\mathrm{c}}$ & $3.113^{\mathrm{d}}$ & $8.758^{\mathrm{a}}$ & $7^{\mathrm{b}}$ \\
\hline DPPH IC $5 \mathbf{5 0}(\boldsymbol{\mu g} / \mathbf{m L})$ & $700^{\mathrm{c}}$ & $1000^{\mathrm{a}}$ & $380^{\mathrm{d}}$ & $780^{\mathrm{b}}$ \\
\hline FRAP EC $\mathbf{5 0}(\mathbf{m g} / \mathbf{m L})$ & $11.73^{\mathrm{a}}$ & $12.6^{\mathrm{a}}$ & $9^{\mathrm{b}}$ & $10.66^{\mathrm{ab}}$ \\
\hline $\begin{array}{l}\boldsymbol{\beta} \text {-carotene bleaching inhibition } \\
\text { activity IC }\end{array}$ & $13^{\mathrm{50}}(\mathrm{mg} / \mathbf{m L})$ & $13.8^{\mathrm{a}}$ & $11^{\mathrm{b}}$ & $12.7^{\mathrm{a}}$ \\
\hline
\end{tabular}

\subsubsection{Antioxidant Activities}

Antioxidant activity of natural extracts were attributed to several mechanisms. In fact, the antioxidant power of fresh Red Globe and Muscat d'Italie extract were measured by four different antioxidant assays: TAA, DPPH, $\beta$-carotene and FRAP (ferric reducing antioxidant power) methods, which are often used because they are simple, inexpensive and robust techniques. Total antioxidant activity of Red grape and Green grape differed greatly between studied extracts depending on the extraction method (Table 1). UAE showed the highest TAA than maceration for the two varieties of grape. Furthermore, results analysis depicted that this ability was much higher in Red grape regardless the method of extraction.

Concerning the antiradical activity of the analyzed extracts, $\mathrm{IC}_{50}$ values ranged between 380 and 1000 $\mu \mathrm{g} / \mathrm{mL}$ (Table 1). The ultrasonic extract of fresh Red grape was the most potent against DPPH synthetic radical $\left(\mathrm{IC}_{50}=380 \mu \mathrm{g} / \mathrm{mL}\right.$ ). Compared to the Green grape extracts, the Red grape extracts were always more effective to quench DPPH radical for the two method of extraction.

The same tendency as DPPH test was observed for the FRAP and $\beta$-carotene bleaching test (Table1). As shown in table 1, ultrasound assisted extraction displayed the best iron reducing power with the lowest $\mathrm{EC}_{50}$ value for red and green grape $\left(\mathrm{EC}_{50}=9 \mathrm{mg} / \mathrm{mL}\right.$ and $10.66 \mathrm{mg} / \mathrm{mL}$ respectively). For the $\beta$ carotene bleaching test, $\mathrm{IC}_{50}$ value were comprised between 11 and $13.8 \mathrm{mg} / \mathrm{mL}$. Ultrasonic extract of fresh red grape exhibited the highest inhibition of linoleic acid oxidation $\left(\mathrm{IC}_{50}=11 \mathrm{mg} / \mathrm{mL}\right)$ as compared to the maceration extracts. These results exhibit that employing ultrasound assisted extraction can improve the antioxidant activities of grapes. In fact, it can be noted that the extraction process affected the antioxidant capacities in a similar way to that observed for the total phenolic content with the superiority of ultrasound assisted extraction, in which mass transfer was intensified by cavitation effect, as compared to the classical method of extraction Delfanian et al. (2015) [33]. These results correspond to the assumption that the antioxidant capacity of the plant extracts is associated significantly with their phenolic content [34;29].

The result of this first part of our study presented a clear advantage on intensification of the extraction of antioxidants by using ultrasound assisted extraction. For this reasons we choose this method for the rest of our research. Nevertheless, several factors influenced the efficiency of the process, such as the physical condition of plant material and power of ultrasound that have to be studied.

\subsection{Drying Effect on Two Varieties Grapes Phenolic Contents and Antioxidant Capacities}

In the second step, the effect of pretreatment of plant material on the efficiency of ultrasound assisted extraction was studied.

\subsubsection{Total Phenolic, Flavonoid and Condensed Tannin Contents}

The total polyphenol, flavonoid and tannins contents of fresh and dried grapes (Red and Green) were quantified and the results are shown in Table 2. All phenolic fraction contents were significantly $(\mathrm{p} \leq$ 0.05 ) affected by the pretreatment. After drying, total polyphenol content of Red and Green grapes was 12 to 16 times higher (9.9 mg EAG/gDW and $4.2 \mathrm{mg}$ EAG/gDW, respectively) than in fresh Red and green grapes $(0.62 \mathrm{mg}$ EAG/gDW and $0.36 \mathrm{mg}$ EAG/gDW, respectively, results were converted to dry weight considering the water content which is $80 \%$ of grape fruit weight). Similarly, total flavonoid and condensed tannins content increased after drying regardless variety. Overall, phenolic, flavonoid and condensed tannin content of Red and Green grapes were highly improved after drying at $40^{\circ} \mathrm{C}$. Drosou et al. (2015) showed that, dry grape pomace extracted with water exhibited higher yield than the untreated grape pomace [35], since drying causes breakage and destruction of cell walls and consequently large cavities and intercellular spaces are formed allowing to the cellular substances to be easily extracted [36]. 
Extraction Methodology and Power Ultrasound Effects on Phenolic Compounds and Antioxidant Activities of Two Tunisian Grape Varieties

Table2. Effect of drying on the extraction yields of phenolic compounds and on the antioxidant activities of Red and Green grapes. TPC: Total polyphenol content, TFC: total flavonoid content, CTC: Condensed tannins content and TAA: Total antioxidant activity. Means of three replicates followed by at least one same letter are not significantly different at $P<0.05$

\begin{tabular}{|l|l|l|l|l|}
\hline Sample & Fresh extract & Dried extract \\
\hline & Red grape & Green grape & Red grape & Green grape \\
\hline TPC (mgEAG/gDW) & $0.62^{\mathrm{c}}$ & $0.36^{\mathrm{d}}$ & $9.9^{\mathrm{a}}$ & $4.2^{\mathrm{b}}$ \\
\hline TFC (mgEC/gDW) & $0.2^{\mathrm{c}}$ & $0.12^{\mathrm{d}}$ & $2.3^{\mathrm{a}}$ & $1.5^{\mathrm{b}}$ \\
\hline CTC (mgEC/gDW) & $0.68^{\mathrm{b}}$ & $0.4^{\mathrm{d}}$ & $9.3^{\mathrm{a}}$ & $2.1^{\mathrm{c}}$ \\
\hline TAA (mgEAG/gDW) & $1.76^{\mathrm{c}}$ & $1.4^{\mathrm{d}}$ & $16.9^{\mathrm{a}}$ & $13^{\mathrm{b}}$ \\
\hline DPPH IC50 $(\boldsymbol{\mu g} / \mathbf{m L})$ & $380^{\mathrm{c}}$ & $780^{\mathrm{a}}$ & $250^{\mathrm{d}}$ & $340^{\mathrm{b}}$ \\
\hline FRAP EC $\mathbf{5 0}(\mathbf{m g / m L )}$ & $9^{\mathrm{b}}$ & $10.66^{\mathrm{a}}$ & $4^{\mathrm{d}}$ & $6.8^{\mathrm{c}}$ \\
\hline $\begin{array}{l}\text { B-carotene bleaching } \\
\text { inhibition activity IC } \\
\text { (mg) }\end{array}$ & $11^{\mathrm{b}}$ & $12.7^{\mathrm{a}}$ & $6^{\mathrm{d}}$ & $10^{\mathrm{c}}$ \\
\hline
\end{tabular}

Means of three replicates followed by at least one same letter are not significantly different at $P<0.05$.

\subsubsection{Antioxidant Activities}

Table 2. gathers the statistical analysis of the antioxidant activities of fresh and dried extracts of Red and Green grapes. A significant difference was found between untreated and dried extract. Total antioxidant activity of red and green grape was significantly $(\mathrm{p} \leq 0.05)$ lower in the fresh extract $(1.76$ and $1.4 \mathrm{mg} \mathrm{EAG/g} \mathrm{DW,} \mathrm{respectively)} \mathrm{as} \mathrm{compared} \mathrm{to} \mathrm{dried} \mathrm{extract} \mathrm{(16.9} \mathrm{and} 13 \mathrm{mg} \mathrm{EAG/gDW,}$ respectively). Similar results was also observed for DPPH radical scavenging activity, since dried extracts was more effective $\left(\mathrm{IC}_{50}=250 \mu \mathrm{g} / \mathrm{mL}\right.$ for Red grape and $\mathrm{IC}_{50}=340 \mu \mathrm{g} / \mathrm{mL}$ for Green grape) than the fresh extracts $\left(\mathrm{IC}_{50}=380 \mu \mathrm{g} / \mathrm{mL}\right.$ for Red grape and $\mathrm{IC}_{50}=780 \mu \mathrm{g} / \mathrm{mL}$ for Green grape). As for the radical-scavenging activities, the iron reducing power of the dried extracts of the two varieties of grape showed the best antiradical activity with the lowest $\mathrm{EC}_{50}$ values $\left(\mathrm{EC}_{50}=4 \mathrm{mg} / \mathrm{mL}\right.$ for Red grape and $\mathrm{EC}_{50}=6.8 \mathrm{mg} / \mathrm{mL}$ for Green grape), while the untreated extracts of Green grape displayed the lowest activity with an $\mathrm{EC}_{50}$ over than $10.66 \mathrm{mg} / \mathrm{mL}$. $\mathrm{IC}_{50}$ values of the $\beta$-carotene bleaching test were comprised between $6 \mathrm{mg} / \mathrm{mL}$ and $12.7 \mathrm{mg} / \mathrm{mL}$. In fact, dried extract exhibited the highest inhibition of linoleic acid oxidation $\left(\mathrm{IC}_{50}=6 \mathrm{mg} / \mathrm{mL}\right.$ for Red grape, $\mathrm{IC}_{50}=10 \mathrm{mg} / \mathrm{mL}$ for Green grape) as compared to the other extracts. These results support previous antioxidant tests, since dried extracts always presents the highest antioxidant content and antioxidant capacities regardless variety of grape. At the whole, our results displayed that the pretreatment (drying) can improve the antioxidant activities of grape. Our findings are in agreement with previous studies showing that drying not only increase the phenolic contents but also retains the antioxidants properties [37]. Investigations related to the ultrasound assisted extraction of antioxidants from Rosmarinus officinalis using dried leaves and fresh leaves of the herb indicated that the extraction of dried herb was better as compared to fresh material which may be attributed to the presence of water in the fresh herb [27].

\subsection{Effect of Ultrasound Power on Two Varieties Grapes Phenolic Contents and Antioxidant Activities}

Ultrasound processing presents a certain number of parameters that should be carefully studied since they can influence the process. Besides the parameters intrinsically related to the ultrasonic device such as the frequency, wavelength, and amplitude of the wave, the ultrasonic power and consequent intensity have also an effect on the process and can be optimized. In this part, the efficiency of extraction power of ultrasound on the total polyphenols, flavonoids and proanthocyanidines and on the antioxidant activities of dried Red and Green grapes were evaluated. Extracts were made at four power settings expressed as a percentage of full power (40,60,80 and 100\%). As shown in Table 3. no significant differences are detected between the different power applied on the phenolic contents and also on the antioxidant activities of the two varieties of grape. The recovery of total phenolics displayed a small but steady increase when ultrasound power was raised from 40 to $100 \%$ (ie. Total polyphenol content $=$ $8,877 \mathrm{mg} \mathrm{EAG/gDW}$ with power of $40 \%$ and $9.9 \mathrm{mg}$ EAG/gDW with a power of $100 \%)$. The same tendency as phenolic contents is observed for DPPH and FRAP assays. In fact, regarding the four tested power $(40,60,80$, and $100 \%)$, it can be noted that most of the extraction is achieved within $40 \%$. Increasing the ultrasound power up to $100 \%$ does not lead to a drastic increase of the polyphenol, 
flavonoid and condensed tannin contents and on antioxidant activities. Ma et al. (2008) reported no significant differences $(p>0.05)$ for total phenolic content of mandarin peel extracts obtained at a ultrasound power up to $200 \mathrm{~W} / \mathrm{L}$, when increasing this variable from 80 to $1400 \mathrm{~W} / \mathrm{L}$. Nevertheless, results reported for ultrasound assisted extraction of phenolics from pomegranate peels [38], grapes [39] and olive leaves [40], showed a higher phenolic yields with increasing ultrasonic power. The same effect was observed for ultrasound assisted extraction of some individual phenolic acids from mandarin peels [41], flavanone glycosides from orange peels [29], oil from grape seeds [42] and $\beta$-carotene from algae Spirula platensis [42].

Table3. Total phenolic contents and antioxidant activities of Red Globe and Muscat d'Italie at four different ultrasonic power (40, 60, 80 and 100\%). TPC: Total polyphenol content, TFC: total flavonoid content, CTC: Condensed tannins content and TAA: Total antioxidant activity. Means of three replicates followed by at least one same letter are not significantly different at $P<0.05$

\begin{tabular}{|c|c|c|c|c|c|c|c|c|}
\hline Sample & \multicolumn{4}{|c|}{ Red grape } & \multicolumn{4}{|c|}{ Green grape } \\
\hline Power (\%) & 40 & 60 & 80 & 100 & 40 & 60 & 80 & 100 \\
\hline TPC (mgEAG/gDW) & $8.877^{\mathrm{a}}$ & $9.01^{\mathrm{a}}$ & $9.127^{\mathrm{a}}$ & $9.99^{a}$ & $1.67^{\mathrm{b}}$ & $1.91^{\mathrm{b}}$ & $2.04^{b}$ & $2.05^{b}$ \\
\hline TFC (mgEC/gDW) & $2.105^{\mathrm{a}}$ & $2.11^{\mathrm{a}}$ & $2.307^{\mathrm{a}}$ & $2.3^{\mathrm{a}}$ & $1.32^{\mathrm{a}}$ & $1.38^{\mathrm{a}}$ & $1.48^{\mathrm{a}}$ & $1.5^{\mathrm{a}}$ \\
\hline CTC (mgEC/gDW) & $8.877^{\mathrm{a}}$ & $9.01^{\mathrm{a}}$ & $8.127^{\mathrm{a}}$ & $9.29^{a}$ & $1.67^{\mathrm{b}}$ & $1.91^{\mathrm{b}}$ & $2.04^{b}$ & $2.05^{b}$ \\
\hline TAA(mgEAG/gDW) & $16.1^{\mathrm{a}}$ & $16.2^{\mathrm{a}}$ & $16.92^{\mathrm{a}}$ & $16.93^{\mathrm{a}}$ & $12.4^{b}$ & $12.95^{b}$ & $13.02^{b}$ & $13^{b}$ \\
\hline DPPH IC ${ }_{50}(\mu \mathrm{g} / \mathrm{mL})$ & $260^{a}$ & $260^{a}$ & $250^{\mathrm{a}}$ & $250^{\mathrm{a}}$ & $360^{\mathrm{a}}$ & $350^{\mathrm{a}}$ & $340^{\mathrm{a}}$ & $340^{\mathrm{a}}$ \\
\hline FRAPEC $_{50}(\mathrm{mg} / \mathrm{mL})$ & $4.1^{\mathrm{a}}$ & $4^{a}$ & $4^{a}$ & $4^{a}$ & $7.2^{b}$ & $7.2^{b}$ & $7^{b}$ & $6.8^{b}$ \\
\hline
\end{tabular}

Means of three replicates followed by at least one same letter are not significantly different at $P<0.05$.

\subsection{Identification of Phenolic Compounds of Red Grape by RP-HPLC Assay}

Phenolic compounds of dried red and green grape extracts obtained by UAE were identified using the HPLC method. According to the retention time of calibration standards, red grape extract showed a chemical profile composed by thirteen identified phenolic compounds (Figure 1), while twelve phenolic compound were identified in the green grape extract (Figure 2). Results showed that the major identified compounds in the red grape were rutin and rosmarinic acid. However, the major compounds of green grape were gallic acid, coumaric and rosmarinic acid. The attendance of these compounds in grape extracts approved the interesting biological activity of this species. In fact, rutin is an interesting flavonoid which exerts a wide variety of biological effects, including antioxidant and free radicalscavenging activities as well as anti-diabetic, anti-inflammatory and anticancer properties $[43 ; 44 ; 45$; 46; 47]. Rosmarinic acid has also a range of biological activities such as antioxidant, anti-inflammatory [48] and anti-cancer properties [49], making it an interesting material for the pharmaceutical, food, and cosmetics industries.

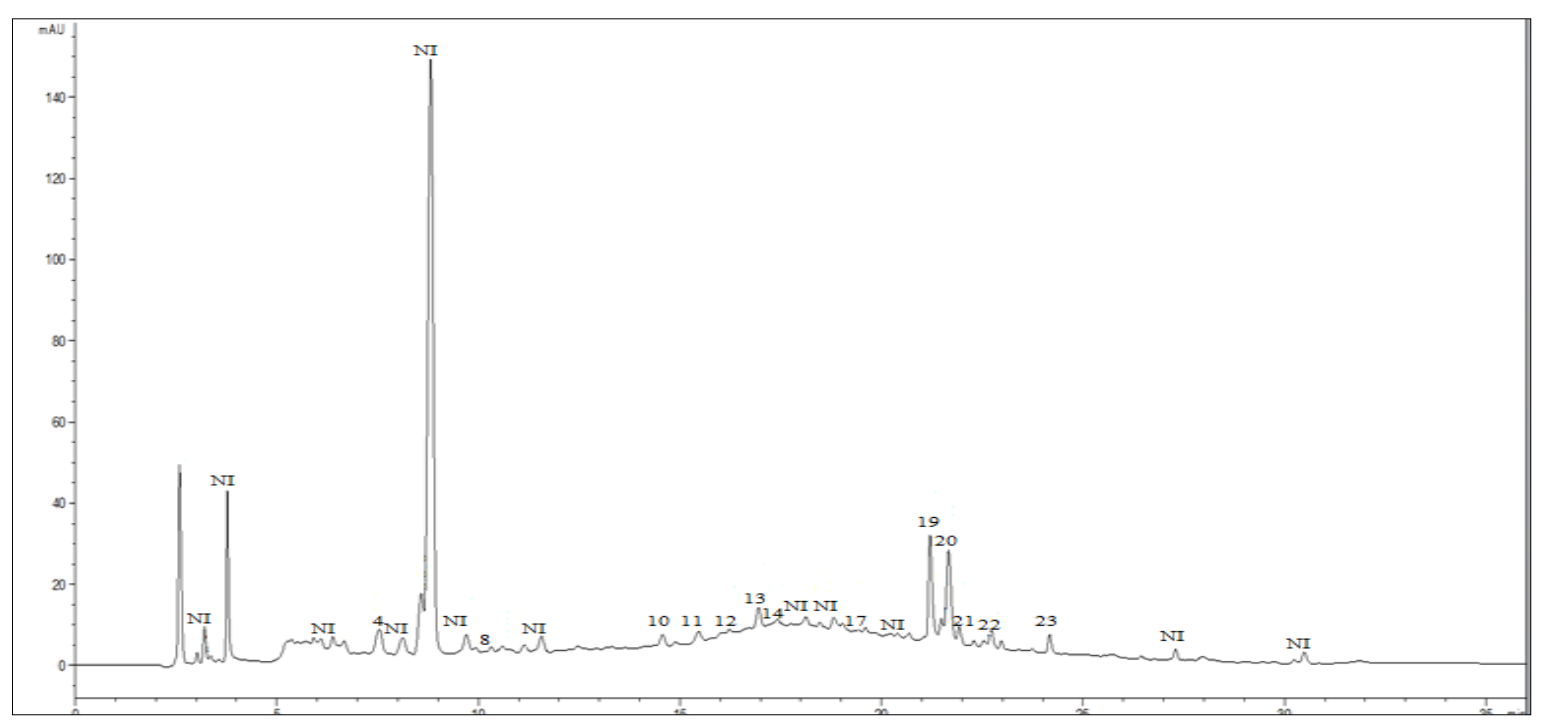

Figure1. RP-HPLC chromatogram of dried red grape extract with power of 40\%. Peaks : 4-Gallic acid; 8Resorcinol; 10-Epigallocatechine ; 11-Chlorogenic acid; 12-Epicatechin-3-O-gallate; 13-Cafeic acid; 14 Syringinic acid ; 17-p-Coumaric acid; 19-Rutin ; 20-Rosmarinic acid; 21-Isoquercetin; 22-kaempferol 3-Orutinoside ; 23-Quercetin ; NI, Not determined. 




Figure2. RP-HPLC chromatogram of dried green grape extract with power of 40\%. Peaks : 5-Gallic acid; 8Resorcinol; 11-Epigallocatechine ; 13-Chlorogenic acid; 15-Epicatechin-3-O-gallate; 17-Cafeic acid; 18 coumarin; 19-Rosmarinic acid; 20-Myricetin; 21 - Isorhamnetin $3 O$ rutinoside ; NI, Not determined.

\section{CONCLUSION}

The ultrasonic assisted extraction of antioxidant compounds from grape fruits was more efficient compared to the conventional methods. In fact, the phenolic contents and the antioxidant capacities were significantly increased using UAE. The effectiveness of ultrasound-assisted extraction of the phenolic compounds present in grape fruits was shown to depend on the drying process applied to grape fruits. In fact, drying has improved notably the quantities of natural antioxidant and their antioxidant activities. Moreover, ultrasound-assisted extraction carried out at 40, 60, 80 and $100 \%$ of power produced similar recoveries of phenolic contents.

The RP-HPLC data revealed a large number of phenolic acids and flavonoids in grape fruits with coumarin, rutin and rosmanic acid as identified phenolics. As a whole, our results suggest that

UAE is a promising method for phenolics' extraction.

\section{ACKNOWLEDGEMENTS}

This work was supported by the Tunisian Ministry of Higher Education and Scientific Research (LR15CBBC06)

\section{REFERENCES}

[1] Shahidi F and Zhong Y., Novel antioxidants in food quality preservation and health promotion, Eur. J. Lipid Sci. Technol. 112, 930 (2010)

[2] Pellegrini N., Serafini M., Colombi B., Del Rio D., Salvatore, S., Bianchi, M., Brighenti, F., Total Antioxidant Capacity of Plant Foods, Beverages and Oils Consumed in Italy Assessed by Three Different In Vitro Assays, J Nutr . 133, 2812 (2003)

[3] Hammi K.M., Jdey A., Abdelly C., Majdoub H., Ksouri R., Optimization of ultrasound-assisted extraction of antioxidant compounds from Tunisian Zizyphus lotus fruits using response surface methodology, Food Chem. 184, 80 (2015)

[4] Gomez-Estaca J., Lopez-de-Dicastillo C., Hernandez-Munoz P., Catala R., Gavara R., Advances in antioxidant active food packaging, Trends Food Sci. Technol. 35, 42 (2014)

[5] Lapornik B., Prosek M., Wondra A.G., Comparison of extracts prepared from plant by-products using different solvents and extraction time, J. Food Eng. 71, 214 (2005)

[6] Spigno G., Tramelli L., De-Faveri D.M., Effects of extraction time, temperature and solvent on concentration and antioxidant activity of grape marc phenolics, J. Food Eng. 81, 200 (2004)

[7] Goli A.H., Barzegar M., Sahari M.A., Antioxidant activity and total phenolic compounds of pistachio (Pistachia vera) hull extracts, Food Chem. 92, 521 (2005)

[8] Both S., Chemat F., Strube J., Extraction of polyphenols from black tea-conventional and ultrasound assisted extraction, Ultrason Sonochem. 21, 1030 (2014) 
[9] Wang L., Weller C.L., 2006. Recent advances in extraction of nutraceuticals from plants. Trends Food Sci. Technol. 17: 300.

[10] Chen X.P., Wang W.X., Li S.B., Xue J.L., Fan L.J., Sheng Z.J., Optimization of ultrasound-assisted extraction of Lingzhi polysaccharides using response surface methodology and its inhibitory effect on cervical cancer cells Carbohydr, Polym J. 80, 944 (2010)

[11] Jakopic J., Colaric M., Veberic R., Hudina M., Solar A., Stampar F., How much do cultivar and preparation time influence on phenolics content in walnut liqueur?, Food Chem. 104, 100 (2007)

[12] Rostagno M.A., Palma M., Barroso C.G., Ultrasound-assisted extraction of soy isoflavones, J. Chromatogr A. 1012,119 (2003)

[13] Cho Y.J., Hong J.Y., Chun H.S., Lee S.K., Min H.Y., Ultrasonication-assisted extraction of resveratrol from grapes, J. Food Eng. 77, 725-30 (2006)

[14] Ghafoor K., Jung J.E., Choi Y.H., Effects of gellan, xanthan, and ë-carrageenan on ellagic acid sedimentatikon, viscosity, and turbidity of 'Campbell Early' grape juice, Food Sci. Biotechnol. 17, 80-84 (2008)

[15] Sánchez-Alonso I., Jiménez-Escrig A., Saura-Calixto F., Borderías A.J., Antioxidant protection of white grape pomace on restructured fish products during frozen storage, JFST. 41, 42-50 (2008)

[16] En-Qin X., Gui-Fang D., Ya-Jun G., and Hua-Bin L., Biological Activities of Polyphenols from Grapes, Int J Mol Sci. 11, 622-646 (2010)

[17] Yilmaz Y., Toledo R.T., Health aspects of functional grape seed constituents, Trends Food Sci. Technol. 15, 422-433 (2004)

[18] Meyer A.S., Yi O.S., Pearson D.A., Waterhouse A.L., Frankel E.N., Inhibition of low-density lipoprotein oxidation in relation to composition of phenolic antioxidants in grapes (Vitis vinifera), J. Agric. Food Chem. 45, 1638-1643 (1997)

[19] Dewanto V., Wu X., Adom K.K., Liu R.H., Thermal processing enhances the nutritional value of tomatoes by increasing total antioxidant activity, J. Agric. Food Chem.. 50, 3010-3014 (2002)

[20] Sun B., Richardo-da-Silvia J.M., Spranger I., Critical factors of vanillin assay for catechins and proanthocyanidins, J. Agric. Food Chem. 46, 4267-4274 (1998)

[21] Prieto P., Pineda M., Aguilar M., Spectrophotometric quantitation of antioxidant capacity through the formation of a phosphomolybdenum complex: specific application to the determination of vitamin $\mathrm{E}$, Anal. Biochem. 269, 337-341 (1999)

[22] Hanato T., Kagawa H., Yasuhara T., Okuda T., Two new flavonoids and other constituents in licorice root their relative astringency and radical scavenging effect, Chem. Pharm. Bull. 36, 1090-1097 (1988)

[23] Oyaizu M., Studies on products of browning reaction: Antioxidative activity of products of browning reaction, JPN J nutr. 44, 307-315 (1986)

[24] Koleva I.I., Teris A.B., Jozef P.H., Linssen A.G., Lyuba N.E., Screening of plant extracts for antioxidant activity: a comparative study on three testing methods, Phytochem. Anal. 13, 8-17 (2002)

[25] Saada M., Falleh H., Jalleli I., Snoussi M., Ksouri R., Phenolic profile, biological activities and fraction analysis of

the medicinal halophyte Retama raetam, S. Afr. J. Bot.. 94, 114-121 (2014)

[26] Albu S., Joyce E., Paniwnyk L., Lorimer J.P., Mason T.J., Potential for the use of ultrasound in the extraction of antioxidants from Rosmarinus officinalis for the food and pharmaceutical industry, Ultrason Sonochem. $11,261-265$ (2004)

[27] Shirsath S.R., Sonawane S.H., Gogate P.R., Intensification of extraction of natural products using ultrasonic irradiations-A review of current status, Chem Eng Process. 53, 10-23 (2012)

[28] Wang H.C., Hu Z.Q., Wang Y., Chen H-B., Huang X.M., Phenolic compounds and the antioxidant activities in litchi pericarp: Difference among cultivars, Sci Hort. 129, 4784-789 (2011)

[29] Khan M.K., Abert-Vian M., Fabiano-Tixier A.S., Dangles O., Chemat F., Ultrasound-assisted extraction of polyphenols (flavanone glycosides) from orange (Citrus sinensis L.) peel, Food Chem. 119, 851-858 (2010)

[30] Herrera M.C., Luque de Castro M.D., Ultrasound-assisted extraction for the analysis of phenolic compounds in strawberries, Anal Bioanal Chem. 379, 1106-1112 (2004)

[31] Li H., Chen., Yao S., Application of ultrasonic technique for extracting chlorogenic acid fromEucommia ulmodies Oliv. (E. ulmodies), Ultrason Sonochem. 12, 295-300 (2005)

[32] Yang Y., Zhang F., Ultrasound-assisted extraction of rutin and quercetin from Euonymus alatus(Thunb.) Sieb, Ultrason Sonochem. 15, 308-313 (2008)

[33] Delfanian M., Kenari R.E., Sahari M.A., Influence of extraction techniques on antioxidant properties and bioactive compounds of loquat fruit (Eriobotrya japonica Lindl.) skin and pulp extracts, Food Sci Nutr. 3, 179-187 (2015) 
[34] González-Centeno M.R., Knoerzer K., Sabarez H., Simal S., Rosselló C., Femenia A., Effect of acoustic frequency and power density on the aqueous ultrasonic-assisted extraction of grape pomace (Vitis viniferaL.) - A response surface approach, Ultrason Sonochem. 21, 2176-2184 (2014)

[35] Drosou C., Kyriakopoulou K., Bimpilas A., Tsimogiannis D., Krokida M., A comparative study on different extraction techniques to recover red grape pomace polyphenols from vinification byproducts, Ind Crops Prod. 75, 141-149 (2015)

[36] Aguilera M., Stanley D.W., 1999. Microstructural principles of food processing and engineering (2nd ed.). Aspen Publishers.

[37] Patel P., Sunkara R., Walker L.T., Verghese M., Effect of Drying Techniques on Antioxidant Capacity of Guava Fruit, J F N S. 7, 544-554 (2016)

[38] Pan Z., Qu W., Ma H., Atungulu G.G., McHugh T.H., Continuous and pulsed ultrasound-assisted extractions of antioxidants from pomegranate peel, Ultrason Sonochem. 18, 1249-1257 (2011)

[39] Carrera C., Ruiz-Rodríguez A., Palma M., Barroso C.G., Ultrasound assisted extraction of phenolic compounds from grapes, Anal Chim Acta. 732, 100-104 (2012)

[40] Ahmad-Qasem M.H., Cánovas J., Barrajón-Catalán E., Micol V., Cárcel J.A., García-Pérez J.V., Kinetic and compositional study of phenolic extraction from olive leaves (var. Serrana) by using power ultrasound, I F S E T. 17, 120-129 (2013)

[41] Ma Y.Q., Ye X.Q., Fang Z.X., Chen J.C., Xu G.H., Liu D.H., Phenolic compounds and antioxidant activity of extracts from ultrasonic treatment of Satsuma mandarin (Citrus unshiu Marc.) peels, J. Agric. Food Chem. 56, 5682-5690 (2008)

[42] Da Porto C.D., Porretto E., Decorti D., Comparison of ultrasound-assisted extraction with conventional extraction methods of oil and polyphenols from grape (Vitis vinifera L.) seeds, Ultrason Sonochem. 20, 10761080 (2013)

[43] Patil S.L., Rao N.B., Somashekarappa H.M., Rajashekhar K.P., Antigenotoxic potential of Rutin and Quercetin in swiss mice exposed to gamma radiation, Biomed J. 37, 305-313 (2014)

[44] Niture N.T., Ansari A.A., Naik S.R., Anti-hyperglycemic activity of rutin in streptozotocin-induced diabetic rats: an effect mediated through cytokines, antioxidants and lipid biomarkers, Indian J Exp Biol. 52, 720-727 (2014)

[45] Choi K.S., Kundu J.K., Chun K.S., Na H.K., Surh Y.J., Rutin inhibits UVB radiation-induced expression of COX-2 and iNOS in hairless mouse skin: p38 MAP kinase and JNK as potential targets, Arch Med Res. 559, $38-45$ (2014)

[46] Alonso-Castro A.J., Dominguez F., Garca-Carranc A., Rutin exerts antitumor effects on nude mice bearing SW480 tumor, Arch Med Res. 44, 346-351 (2013)

[47] Nassiri-Asl M., Naserpour Farivar T., Abbasi E., Sadeghnia H.R., Sheikhi M., Lotfizadeh M., Effects of rutin on oxidative stress in mice with kainic acid-induced seizure, J Integr Med. 11, 337-342 (2013)

[48] Sotnikova R., Okruhlicova L., Vlkovicova J., Navarova J., Gajdacova B., Krenek P., Rosmarinic acid administration attenuates diabetes-induced vascular dysfunction of the rat aorta, J Pharm and Pharmacol. 65, 713-23 (2013)

[49] Venkatachalam K., Gunasekaran S., Jesudoss V.A., Namasivayam N., The effect of rosmarinic acid on 1,2dimethylhydrazine induced colon carcinogenesis, Exp. Toxicol. Pathol. 65, 409-18 (2013)

Citation: Saada Mariem, et.al., (2021). "Extraction Methodology and Power Ultrasound Effects on Phenolic Compounds and Antioxidant Activities of Two Tunisian Grape Varieties". International Journal of Medicinal Plants and Natural Products (IJMPNP), 7(1), pp.9-18. https://doi.org/ 10.20431 /24547999.0701002

Copyright: (C) 2021 Authors. This is an open-access article distributed under the terms of the Creative Commons Attribution License, which permits unrestricted use, distribution, and reproduction in any medium, provided the original author and source are credited. 